\title{
Medication errors reported in a tertiary care private hospital in Eastern India: a three years experience
}

\author{
Subhrojyoti Bhowmick ${ }^{1}$, Shubham Jana ${ }^{1 *}$, Adrija Bandyopadhyay ${ }^{1}$, Debarati Kundu', \\ Meena Banerjee' ${ }^{2}$, Anupam Das ${ }^{3}$, Sujit KarPurkayastha ${ }^{4}$
}

${ }^{1}$ Department of Clinical Research, ${ }^{2}$ Department of Nursing, ${ }^{3}$ Department of Quality Assurance and Medical Administration, ${ }^{4}$ Department of Gastroenterology, Peerless Hospitex Hospital and Research Center Ltd., Kolkata, West Bengal, India

Received: 29 March 2020

Revised: 29 April 2020

Accepted: 30 April 2020

*Correspondence:

Mr. Shubham Jana,

Email: sjana9424@gmail.com

Copyright: (c) the author(s), publisher and licensee Medip Academy. This is an open-access article distributed under the terms of the Creative Commons Attribution Non-Commercial License, which permits unrestricted non-commercial use, distribution, and reproduction in any medium, provided the original work is properly cited.

\begin{abstract}
Background: Medication errors (MEs) can cause significant harm to patients. The MEs identified through reporting processes currently report only a fraction of the actual number of MEs. Data about MEs is limited in India, especially from eastern and north-eastern parts of India. The objective of this study was to analyse the various types of Medication errors reported in a tertiary care private hospital in Eastern India. The aim was to determine the various factors associated with these errors and steps to be taken to reduce the MEs in this healthcare setup.

Methods: We carried out a prospective passive surveillance study over the course of 3 years $(2016-2018)$ on 50,822 admitted patients after obtaining approval from the Institutional Ethics Committee. A detailed root-cause analysis was performed for every reported error by a team of healthcare quality professionals and clinical pharmacists along with a clinical pharmacologist followed by appropriate preventive and corrective actions.

Results: In our study, a total number of 88 medication errors were reported from a sample size of 50,822 $(0.0017 \%)$. 61 of the reported MEs were administration errors (69.3\%). Higher preponderance of medication errors was seen in male patients $(53.1 \%)$ in comparison to female patients $(46.9 \%)$.

Conclusions: In this study gross under-reporting of MEs were observed which is in line with previously published studies in India. The reasons reported for gross under-reporting can function as an effective tool to ensure improved reporting of MEs and implementation of mitigation strategies.
\end{abstract}

Keywords: Medication error, Eastern India, Private hospital, Administration errors, Prescription error

\section{INTRODUCTION}

Medication errors (MEs) are common in Indian hospitals which can cause significant harm to the patients. ${ }^{1}$ MEs occur at various stages of the medication process which include prescribing, dispensing and administration of a drug to the patient. The aim of medication use is to achieve specific therapeutic effects along with improvement in the quality of life and minimization of patient risk. ${ }^{1,2}$ Errors in this process, can not only increase the morbidity and mortality rate of the patient population but also increase the costs of treatment. Furthermore, errors have the potential to decrease patients' confidence in healthcare delivery system.,

The national coordinating council for medication error reporting and prevention (NCC MERP) has defined medication errors (MEs) as, 'Any preventable event that 
may cause or lead to inappropriate medication use or patient harm while the medication is in the control of the health care professional, patient, or consumer. Such events may be related to professional practice, health care products, procedures, and systems, including prescribing, order communication, product labelling, packaging, and nomenclature, compounding, dispensing, distribution, administration, education, monitoring, and use. $^{5}$ Reporting system plays an important role in diminishing MEs. ${ }^{6}$ It informs about the types of MEs present and types of preventive actions that can be undertaken.

In India, studies done in northern states of the country like Uttarakhand have reported medication error rates to be as high as $25.7 \%$ in hospitalized patients whereas in southern states like Karnataka it was $15.34 \%$. Unfortunately, most of the medication errors remain undetected, in part because they are often not reported. ${ }^{7}$

Very little analysis of medication errors has been done in India, especially in eastern India. The current study is conducted in a private tertiary care hospital in eastern India where no such study has been reported till date. To the best of our understanding, this is the longest ( 3 years) reported period of passive surveillance study of the MEs reporting system being conducted for the first time in Eastern India to analyse causes of medication errors using a very large database of admitted patients, over a threeyear long period (2016-2018).

\section{Objective}

Trivial medication errors (e.g. delay in giving a dose) may result in insignificant changes while the more severe ones (e.g. administration of a contraindicated drug to a patient) can increase patient morbidity and mortality in the hospitals. ${ }^{6}$

\section{Primary objective}

This study was to identify and assess the causes and types of MEs reported in a tertiary care private hospital in eastern India over a three years study period (2016-2018).

\section{Secondary objective}

The study was also to assess the pattern of occurrence of MEs and studying the events which lead to increased occurrence of the same. We also wished to explore the possibilities of developing a more efficient ME reporting system.

\section{METHODS}

A prospective passive surveillance study was carried out on patients admitted in Peerless Hospitex Hospital and Research Center Ltd., a renowned 400 beds tertiary care private multi-specialty hospital, in Kolkata, West Bengal, between January 2016 and December 2018 (3 years). A sample size of 50,822 admitted patients were passively evaluated to analyze the reporting of any medication errors. The data were analyzed by Microsoft excel, version 2007 (Microsoft corporation, Redmond, Washington).

\section{Inclusion criteria}

The criteria for inclusion were any admitted patients within the age group of (2-88) years and admission or treatment period was from January 2016 to December 2018.

\section{Exclusion criteria}

The criteria for exclusion were patients below the age of 2 years or above the age of 88 years, patients in the hospital (OPD), patients from the neurosciences and ophthalmology departments, patients from the neonatal department, and day care patients.

Medication errors were reported by doctors or nurses on an approved medication error reporting form (Figure 1) within 24 hours of awareness. A total number of 88 cases of medication errors were reported during the aforesaid period. A detailed root-cause analysis was performed for the reported errors by a team of healthcare quality professionals and clinical pharmacists along with a clinical pharmacologist to identify the causes of the MEs. The medication error details had been conveyed to the concerned healthcare professionals, and appropriate interventions had been made to treat adverse effects (if any) as well as to prevent such incidents in the future.

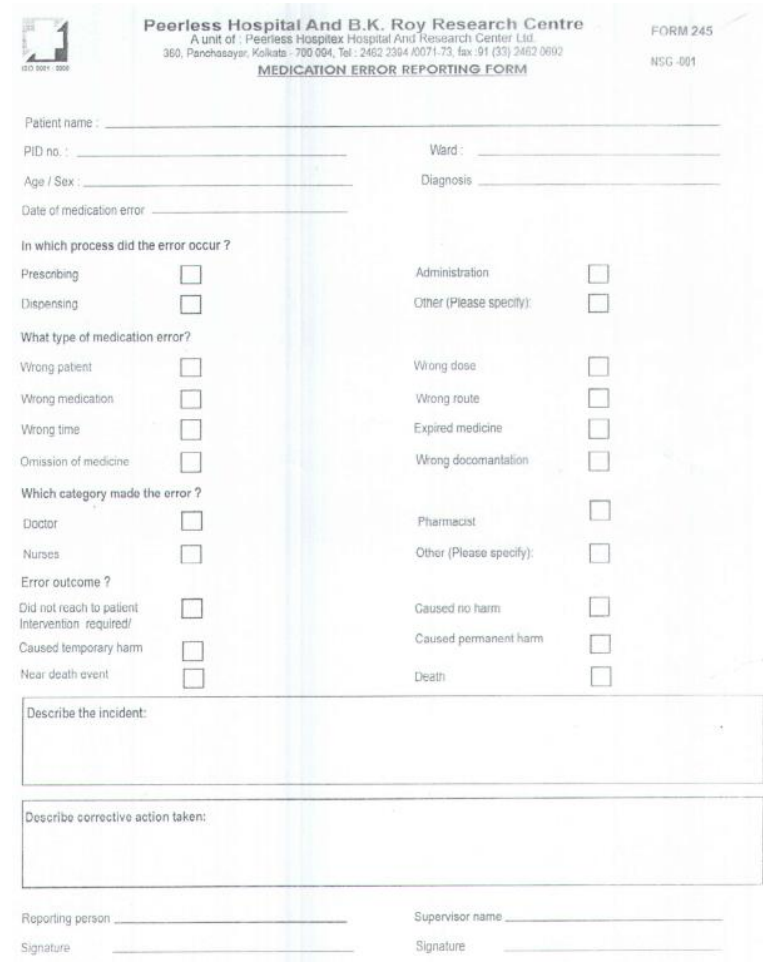

Figure 1: Medication error reporting form. 


\section{RESULTS}

\section{Types of medication errors}

The occurrence of administration errors was found to be in majority and accounted for 61 of the total 88 reported errors. In certain cases, there was more than one type of error that occurred in a single incident of medication error (Table 1).

Table 1: No. of medication errors of each category.

\begin{tabular}{|ll|}
\hline Types of error & No. of errors \\
\hline Prescribing & 5 \\
\hline Administration & 76 \\
\hline Dispensing & 6 \\
\hline Indenting & 1 \\
\hline
\end{tabular}

Table 2: MEs caused by different categories of healthcare professionals and percentage of the total MEs.

\begin{tabular}{|lll|}
\hline $\begin{array}{l}\text { Category of healthcare } \\
\text { professional }\end{array}$ & $\begin{array}{l}\text { No. of } \\
\text { MIES }\end{array}$ & $\begin{array}{l}\text { \% of } \\
\text { MES }\end{array}$ \\
\hline Doctor & 6 & 7.2 \\
\hline Nurse & 76 & 91.6 \\
\hline Pharmacist & 5 & 6.02 \\
\hline Others & 2 & 2.4 \\
\hline
\end{tabular}

\section{Relationship between medication errors and healthcare professionals}

The percentage of MEs caused by the nursing staff was $91.6 \%$, whereas MEs caused by doctors, pharmacists and others (the professionals at the blood bank or kin of the patients) accounted for $7.2 \%, 6.02 \%$ and $2.4 \%$ respectively (Table 2).

\section{Effects of medication error on age group and gender}

As shown in (Table 3), medication errors were most frequent for patients in the age group of (61-70) years and the age group to be least affected was (1-10) years. However, 3 patients affected by MEs were children between ages of 2 and 14 years.

On the other hand, the frequency of medication errors was found to be slightly more inclined to the male patients $(53.1 \%)$ than their female counter-parts $(46.9 \%)$ in the total study population (Table 4).

\section{Common types of administration errors}

Administration error was found to be the most common type of medication error in this study. Out of the 88 reported medication errors, wrong dose error was the most frequently reported type of Administration Error (28.9\%), followed by error due to omission of medicine (19.3\%) as shown in (Table 5 and Figure 2).
Table 3: Age-wise distribution of medication errors $(\mathbf{n}=\mathbf{8 8})$.

\begin{tabular}{|c|c|c|}
\hline $\begin{array}{l}\text { Patient age group } \\
\text { (in years) }\end{array}$ & No. of errors & $\begin{array}{l}\% \text { of } \\
\text { errors }\end{array}$ \\
\hline 01-10 & 1 & 1.3 \\
\hline $11-20$ & 4 & 4.8 \\
\hline $21-30$ & 5 & 5.8 \\
\hline $31-40$ & 6 & 7.4 \\
\hline $41-50$ & 16 & 19.3 \\
\hline $51-60$ & 10 & 12.0 \\
\hline $61-70$ & 22 & 26.5 \\
\hline 71-80 & 11 & 13.3 \\
\hline 81-90 & 8 & 9.6 \\
\hline
\end{tabular}

Table 4: Gender-wise distribution of medication errors $(n=83)$.

\begin{tabular}{|lll|}
\hline Gender & No. of errors & $\begin{array}{l}\text { \% of } \\
\text { errors }\end{array}$ \\
\hline Female & 39 & 46.9 \\
\hline Male & 44 & 53.1 \\
\hline
\end{tabular}

Table 5: Frequency of occurrence of different types of administration errors $(\mathbf{n}=\mathbf{8 8})$.

\begin{tabular}{|lll|}
\hline $\begin{array}{l}\text { Types of administration } \\
\text { error }\end{array}$ & $\begin{array}{l}\text { No. of errors } \\
\text { Wrong documentation }\end{array}$ & $\begin{array}{l}\text { \% of } \\
\text { errors }\end{array}$ \\
\hline Expired medication & 2 & 12.1 \\
\hline Wrong route & 9 & 2.4 \\
\hline Wrong dose & 24 & 10.8 \\
\hline Omission of medicine & 16 & 28.9 \\
\hline Wrong time & 15 & 19.3 \\
\hline Wrong medication & 12 & 18.1 \\
\hline Wrong patient & 2 & 14.5 \\
\hline
\end{tabular}

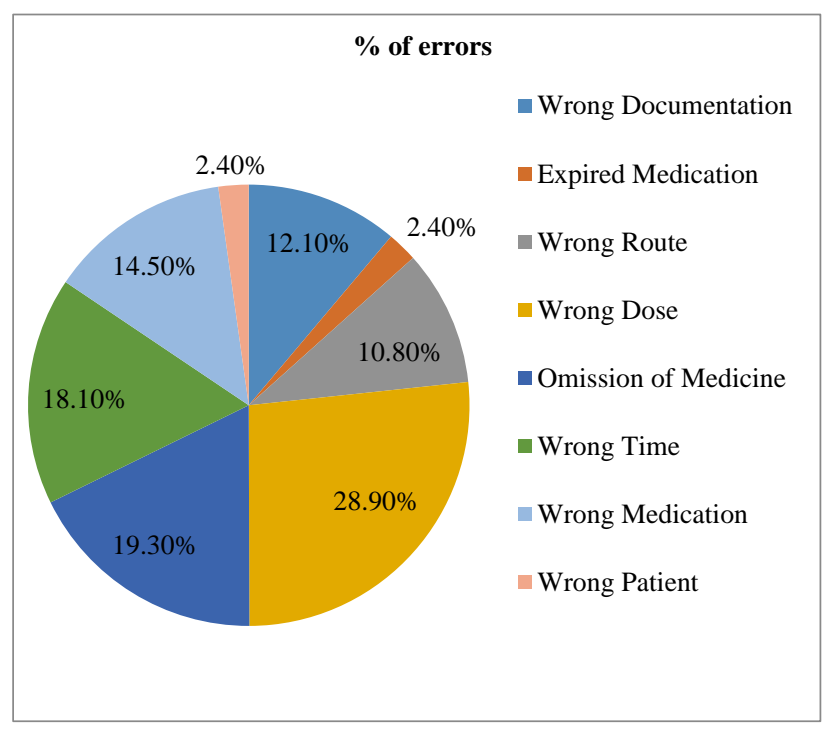

Figure 2: Frequency of occurrence of different types of administration errors. 


\section{Medication error categorization on the basis of NCC MERP index}

The data collected through the Medication Error reporting form suggested that the outcomes of the MEs could be grouped into four categories, as per the NCC MERP index for categorizing medication errors viz. categories B, C, D and E (Table 6).

During the course of the study, the investigators noted that no reports were being passively generated. 50,822 patients were not actively screened for MEs occurrence because investigators wanted to understand the strength and weakness of passive reporting medication error system. Hence this current study, which is passive surveillance in nature, was undertaken to understand reasons of low reporting of MEs and determine the corrective steps which are required to improve reporting.

Table 6: Reported ME categorization based on NCC MERP Index.

\begin{tabular}{|llll|}
\hline $\begin{array}{l}\text { Common error } \\
\text { outcome }\end{array}$ & $\begin{array}{l}\text { Category of } \\
\text { NCC MERP } \\
\text { index }\end{array}$ & $\begin{array}{l}\text { No. of } \\
\text { MEs }\end{array}$ & $\begin{array}{l}\text { \% of } \\
\text { MEs }\end{array}$ \\
\hline $\begin{array}{l}\text { Error did not } \\
\text { reach patient }\end{array}$ & B & 14 & 16.9 \\
\hline $\begin{array}{l}\text { Error reached } \\
\text { patient but did } \\
\text { not cause any } \\
\text { harm }\end{array}$ & C & 61 & 73.5 \\
\hline $\begin{array}{l}\text { Error reached } \\
\text { patient and } \\
\text { caused } \\
\text { temporary harm }\end{array}$ & D, E & 8 & 9.6 \\
\hline
\end{tabular}

\section{DISCUSSION}

This is a 3 years prospective passive surveillance study where the efficiency of the MEs reporting system was assessed. MEs reporting system was implemented in the year 2014 at the study hospital.

In our study, a total number of 88 medication errors were reported. However, none of the MEs resulted in any fatal incident. On the contrary, in a similar study conducted by Reddy et al, the percentage of medication errors was found to be $66.32 \%$ where none of the MEs had any fatal outcome. ${ }^{8}$ The most frequent type of error reported in our study was administration error which accounted for $69.3 \%$ of the total MEs. Prescribing errors and dispensing errors accounted for $6.02 \%$ and $7.2 \%$ of the total MEs, respectively. Of all the administration errors, the majority were reported to be wrong dose errors which accounted for $28.9 \%$ of the total MEs. However, in a study done by Sheikh et al, wrong dose error was reported as the least frequent type of error and omission error was reported as the most frequent type of error. ${ }^{9}$
Medication orders given verbally may easily result in miscommunications which may lead to medication errors. This may consequently result in adverse medical events. ${ }^{6}$ In this study, $3.6 \%$ of the errors were reported to be caused due to the verbal orders given by doctors. However, if verbal medication orders are replaced by hand written orders, errors occurring due to miscommunications can be reduced. Therefore, the error can be prevented before it occurs.

The age group between (61-70) years was found to be the most affected, accounting for $26.5 \%$ of the total medication errors. The age group which was least affected was (1-10) years (1.3\%). In addition, 3 children of ages 2, 12 and 14 years were affected by MEs in this study. Similar trends were reported by Sheikh et al and Rekha et al, where it was found that highest prevalence of medication errors was in older adults, and most of them occurred due to poly-pharmacy and poly-morbidity. ${ }^{10,11}$

In the present study, male patients were slightly more affected by medication errors as compared to female patients. Similar trends were reported by different studies performed in Karnataka, Saudi Arabia and Iran. 7,12

The data collected from the medication error reporting forms reported about the outcomes of the MEs. 61 out of the 88 reported MEs $(69.3 \%)$ did not cause any harm to the patient. 14 MEs $(15.9 \%)$ did not affect the patient as they were detected before administration of medication to the patient. However, 8 incidents of MEs $(9.09 \%)$ caused temporary harm to the patients. According to the NCC MERP Index for categorizing medication errors, 14 MEs which were detected before administration of medication belonged to category B, 61 MEs which did not cause any harm to the patient belonged to category $\mathrm{C}$ and $8 \mathrm{MEs}$ which cause temporary harm to the patient belonged to either category D or category E. ${ }^{5,13}$

A major finding of this study was the gross underreporting of the incidents of MEs. The study was aimed at finding a suitable solution to not only decrease the incidents of non-reporting of MEs, but also to decrease the occurrence of MEs. Reporting errors is necessary for preventing those incidents from happening in the future thereby reducing personal suffering and financial costs. ${ }^{14}$ The reasons reported for gross under-reporting can function as an effective tool to improve ME reporting system in the country.

A very low percentage of medication errors are actually reported. ${ }^{15,16}$ Jolayi et al, in their study (2009) were concerned about the barriers to medication error reporting and emphasized on the importance of the same. ${ }^{17}$

\section{Incidents of non-reporting of MEs may occur due to various reasons such as}

Medication error is perceived as unimportant, reporters have fear of punishment, medication error is not reported 
if patient is not harmed, reporting process is considered long and time consuming.

The above-mentioned reasons remain valid for all categories of healthcare professionals and hence restructuring of the medication error reporting system is required.

\section{Following factors may facilitate the efficient reporting of medication errors}

Maintaining anonymity in a reporting system, perceiving the benefits of reporting MEs, eliminating the fearful atmosphere when reporting a ME, simplifying error reporting by digitalizing the entire process. ${ }^{13,18}$ Introducing web-based forms or adapted standard spreadsheets to reveal patterns of errors. ${ }^{19}$ Sharing the changes made in the medication management system with the error reporter, regular capturing of errors by the pharmacies which are usually the neglected units for occurrence of MEs.

In a previous study, it was shown that intervention is essential to spread awareness amongst Healthcare professionals about reporting MEs and to ensure mandatory reporting of MEs. ${ }^{20}$ The current study is a 3 years passive surveillance study of MEs in a tertiary care private hospital in eastern India which has not been reported in any earlier studies.

Clinical pharmacologists and pharmacists have a major role to play in detecting and preventing medication errors. The hospital pharmacist is trained to monitor the entire drug distribution chain; starting from prescribing, drug choice, dispensing and preparation for administration of drugs, and can play a vital role in improving medication safety. ${ }^{21}$ Participation of a pharmacist in medical rounds is common in many hospitals and has been proven to prevent errors, lower drug costs and reduce ADEs in intensive care units as well as general medicine units. ${ }^{22,23}$ Compared to the traditional approach of checking prescriptions and correcting errors, participation of a pharmacist on medical rounds is expected to be much more effective and challenging and the specific expertise of a pharmacist is therefore much better utilised. ${ }^{21}$

The limitations of the study include active screening not done for all the patients, uni-centric nature of the study and scenario within government hospital was not studied. The strengths of the study include that it is the longest (2016-18) surveillance study reported from eastern India till date from a private healthcare institution which can be considered a representative sample of healthcare facilities across Eastern India as a large number of patients avail health services from private hospitals.

The current research study will add to the epidemiological picture of MEs existing in a vast developing country like India, which has a sizeable disparity amongst the quality of the healthcare facilities. As no such data exists from the eastern part of the country, the investigators believe that their study will add to the national scenario of challenges and issues faced during the ME reporting program.

\section{CONCLUSION}

MEs were found to be common in the tertiary care private hospital from eastern India. There is gross under reporting of MEs if monitored through passive surveillance in the hospital. Although under-reporting was commonly encountered, the investigators believe it could be improved through regular training and awareness campaigns among doctors, nurses, clinical pharmacologists, pharmacists and patients and active surveillance. Preventing medication errors should be the aim of every healthcare professional. We believe this is an important piece of clinical research experience which must be shared with fellow health care professionals of our country and also internationally, so that they can devise their ME reporting strategies efficiently. Larger study involving government hospital set ups is our future plan in order to evaluate the current scenario of medication error reporting from eastern India.

\section{ACKNOWLEDGEMENTS}

We would like to express our heartfelt gratitude to the nursing staff, personnel from the department of clinical research, quality assurance and the doctors of Peerless Hospitex Hospital and Research Center Ltd., Kolkata, West Bengal, India, for their constant cooperation and support during the course of the study.

\section{Funding: No funding sources}

Conflict of interest: None declared

Ethical approval: The study was approved by the Institutional Ethics Committee

\section{REFERENCES}

1. Patel N, Desai M, Shah S, Patel P, Gandhi A. A study of medication errors in a tertiary care hospital. Perspect Clin Res. 2016;7(4):168-73.

2. Hepler CD, Strand LM, Opportunities and responsibilities in pharmaceutical care. Am J Hosp Pharm. 1990;47:533-43.

3. Ministry of Health Malaysia. Guideline on medication error reporting. 1st ed. Malaysia: Ministry of Health Malaysia; 2009.

4. Davis NM, Cohen MR. Medication Errors: Causes and Prevention. Huntingdon Valley, PA: Neil M. Davis Associates; 1981.

5. The National Coordinating Council for Medication Error and Prevention (NCCMERP). The Council: Moving into the Second Decade 'Developing Recommendations and Offering Tools'; 2010.

6. Hermon R, Williams PAH. A Study on Information Induced Medication Errors, SRI Security Research 
Institute, Edith Cowan University, Perth, Western Australia; 2013.

7. Kumar KS, Venkateswarlu K, Ramesh A. A study of medication administration errors in a tertiary care hospital. Indian J Pharm Pract. 2011;4:37-42.

8. Reddy P, Mandha M. Medication errors: identification, prevention and implementation of safe medication practice in a tertiary care teaching hospital. World J Pharm Sci. 2015;4:1249-56.

9. Sheikh D, Mateti UV, Kabekkodu S, Sanal T. Assessment of medication errors and adherence to WHO prescription writing guidelines in a tertiary care hospital. Future J Pharma Sci. 2017;3:60-4.

10. Rekha B, Saurabh B. Evaluation of prevalence of medication errors in a multispecialty teaching hospital, Dehradun. IJOPP. 2013;6:19-24.

11. Ross LM, Wallace J, Paton JY. Medication errors in a paediatric teaching hospital in the UK: five years operational experience. Archives Disease Childhood. 2000;83(6):492-7.

12. Jeraisy AMI, Alanazi MQ, Abolfotouh MA. Medication prescribing errors in a pediatric inpatient tertiary care setting in Saudi Arabia. BMC Res Notes. 2011;4(1):294.

13. National Coordinating Council for Medication Error and Reporting and Prevention. Available at: http://www.nccmerp.org/aboutMedErrors.html. Accessed on $13^{\text {th }}$ May 2019.

14. Wolf ZR, Hughes RG. Error Reporting and Disclosure. In: Hughes RG, editor. Patient Safety and Quality: An Evidence-Based Handbook for Nurses. Rockville (MD): Agency for Healthcare Research and Quality (US); 2008 Apr. Chapter 35. Available at: http://www.ncbi.nlm.nih.gov/ books/NBK2652. Accessed on 3 January 2020.

15. Balas MC, Scott LD, Rogers AE. frequency and type of errors and near errors reported by critical care nurses. Can J Nurs Res. 2006;38(2):24-41.

16. Banja JD. Problematic medical errors and their implications for disclosure. HEC Forum. 2008;20(3):201-13.

17. Jolayi S, Hajibabaei F, Peyrovi H, Haghani $H$. Review and report the occurrence of errors and their association with the working conditions of nurses working in hospitals of Iran University of Medical Sciences. Iranian J Medical Ethics History Med (Persian); 2009.

18. Bayazidi S, Zarezadeh Y, Zamanzadeh V, Parvan K. Medication Error Reporting Rate and its Barriers and Facilitators among Nurses. J Caring Sci. 2012;1(4):231-6.

19. Davis MA, Rake GW. Implementation of a databased medical event reporting system in U.S. department of defense. In: Henriksen K, Battles JB, Marks ES, et al., editors. Advances in patient safety: from research to implementation: Vol. 3. Implementation issues. Surveillance. Rockville, MD: Agency for Healthcare Research and Quality; 2005: 235-244.

20. Bhowmick S, Banerjee K, Sikdar S, Chatterjee TK. An evaluation of knowledge, attitude, and practice of institutional ethics committee members from eastern India regarding ethics committee functioning and pharmacovigilance activities conducted during clinical trials: a pilot study. Perspectives Clin Res. 2014;5(3):115-20.

21. Guchelaar HJ, Colen HBB, Kalmeijer MD, Hudson PTW, Twiss TIM. Medication Errors Drugs. 2005;65(13):1735-46.

22. Leape LL, Cullen DJ, Clapp DM. Pharmacist participation on physician rounds and adverse drug events in the intensive care unit. JAMA. 1999;281(3):267-70.

23. Kucukarslan SN, Peters M, Mlynarek M. Pharmacists on rounding teams reduce preventable adverse drug events in hospital general medicine units. Arch Intern Med. 2003;163(17):2014-8.

Cite this article as: Bhowmick S, Jana S,

Bandyopadhyay A, Kundu D, Banerjee M, Das A, et al. Medication errors reported in a tertiary care private hospital in Eastern India: a three years experience. Int J Basic Clin Pharmacol 2020;9:937-42. 